\title{
Adsorption and Treatment of Petroleum Products Contaminated Water using Activated Carbon Produced from Hura crepitans Linn Seeds
}

\author{
Yelwa Abubakar Sani ${ }^{1}$, Ogbiko Cyril ${ }^{1}$ and Muhammad Aliyu, ${ }^{2, *}$ \\ ${ }^{1}$ Department of Pure and Applied Chemistry, Usmanu Danfodiyo University, Sokoto, Nigeria \\ ${ }^{2}$ Department of Microbiology, Ambrose Alli University, Ekpoma Edo State, Nigeria \\ e-mail: muhammadaliyufla@gmail.com \\ ${ }^{*}$ Corresponding author
}

\begin{abstract}
Industrial waste water arising from crude oil exploration and processing activities poses a serious environmental problem in Nigeria. Consequently, a study of the use of activated carbon in the clean up was designed by this study with the aim of reducing the water contamination to a more acceptable level. Locally produced activated carbon produced from Hura crepitans seeds of different mass was employed as adsorbent with its adsorption potentials compared with standard commercial activated carbon. A $2 \mathrm{~h}$ contact time was allowed after which physicochemical parameters such as temperature, odour, appearance, density, $\mathrm{pH}$, chemical oxygen demand, dissolved oxygen, biological oxygen demand, conductivity, turbidity, total dissolved solids, chloride, sulphate, total hardness, calcium and magnesium concentrations were determined. Results of the analyses showed that the produced activated carbon is an excellent means for the removal of the contaminants as seen by the decrease in the contaminant concentration from an initial concentration to that within or close to both WHO and refinery specifications. The results of this study revealed that the powdered form of the activated carbon from $H$. crepitans seed would be very effective in the remediation of petroleum-hydrocarbon contaminated ground water and its use is therefore recommended.
\end{abstract}

\section{Received: August 26, 2019; Accepted: September 24, 2019}

Keywords and phrases: activated carbon, Hura crepitans, petroleum wastes.

Copyright () 2019 Muhammad Aliyu et al. This is an open access article distributed under the Creative Commons Attribution License, which permits unrestricted use, distribution, and reproduction in any medium, provided the original work is properly cited. 


\section{Introduction}

Industrial wastewater is often contaminated with various compounds such as: phenol, chromium, suspended solids, dissolved organic compounds among others hence it is imperative that it should be treated to an environmental acceptable limit. The current problems in wastewater treatment stem primarily from the increasing pollution of waters by organic compounds that are difficult to decompose biologically, because these substances resist the self-purification capabilities of the rivers as well as decomposition in conventional wastewater treatment plant [1]. Oilfields like most production activities generate large volumes of liquid waste called produced water [2, 3]. It is estimated that globally over seventy billion barrels of produced water is generated by the petrochemical industries annually $[2,4]$. The constituents of discharged water from petroleum activities are broadly classified into organic and inorganic compounds which includes dissolved and dispersed oils, grease, heavy, metals, radionuclides, treatment chemicals, formation solids, dissolved gases, scale products, waxes, microorganisms and dissolved oxygen [2, $5,6]$. The discharge of emerging wastes and pollutants in water bodies is on the rise with increase in industrialization. Wastes from petroleum refining are not only carcinogenic but are bio-accumulative which are not easily biodegraded and hence if discharged into the environment, they could cause environmental and human health effects in addition to the pollution of surface water, ground water and soils [2, 7]. If extensive discharge is done into water bodies, it could cause "chronic pollution" capable of limiting the breeding and reproduction of seabirds [8]. There is therefore the need to treat adequately waste water from petroleum production processes before their discharge to protect water resources and avoid acute and chronic toxicities $[8,9]$. The treatment choice is however dependent on factors such as regulatory acceptance, site location, technical feasibility, cost of equipment and availability of infrastructure $[2,8,10]$ with the management practices suggested to be environmentally friendly in itself.

Hura crepitans Linn. is a tropical plant belonging to the family Euphorbiacea. In Nigeria, it is known as "odan mecca" by the Kabba people of Kogi State and "aroyin" by the Ijesha people of Osun State. H. crepitans is often planted in towns and villages as a shade tree. It has short, densely crowned spines on the trunk and branches; the long stalked leaves with prominent, closely parallel pinnate nerves, the purple flower spikes, and the large fluted flattened fruits are highly distinctive. This tree is up to 90-130 feet high with a wide spreading crown, branching low down. Leaves are 5-20 cm long by 5- 
$15 \mathrm{~cm}$ broad, ovate, shortly and abruptly acuminate, and dark green in color. This tree flowers usually at the beginning of and again at the end of rainy season. One nut is a flattened and fluted disc with five to 20 lobes about $2.5 \mathrm{~cm}$ deep and $7.5 \mathrm{~cm}$ wide on a stout stalk. The capsule splits explosively, releasing one flattened circular seed about 18 mm across from each chamber $[11,12]$.

The traditional treatment of the wastewater effluents from the refinery and petrochemical plants are usually based on the mechanical, physicochemical and biological methods. The conventional processes that are applied for the treatment of petrochemical wastewater can only partially remove the contaminants hence the need for diverse and more advanced treatment techniques [9, 13]. Among the advanced treatment techniques adsorption on activated carbons for waste water treatment has been found superior compared to other chemical and physical methods in use in terms of its capability for efficiently adsorbing a broad spectrum of pollutants, and its simplicity in design [14]. This study was undertaken with the aim of ascertaining the effectiveness of activated carbon from Hura crepitans seeds in adsorbing pollutants from industrial waste water from petroleum production processes viz-a-viz ascertaining the level of certain physicochemical parameters in the effluent waste water.

\section{Materials and Methods}

\section{Sample collection}

Fresh and matured sample of Hura crepitans fruits were collected randomly behind College of Agriculture, Agenebode Etsako East Local Government Area of Edo State Nigeria. The samples were transported to the laboratory in clean polythene bag with its identity confirmed by a taxonomist

\section{Sample preparation}

The plant fruits were broken manually to release its seeds. The seeds were washed with running tap water to remove the contaminants before being shade dried for seven days. Good and matured seeds of variable sizes were manually selected and grounded into powder using an electric milling machine. The powered seeds sample was stored in an air tight glass container until use.

\section{Preparation of activated carbon}

The procedure as outlined by Ali et al. [15] was adopted with slight modification. 
$500 \mathrm{~g}$ of the pulverized $H$. crepitans seed powder was placed in a crucible and covered by $600 \mathrm{~g}$ of sand. The crucible was heated in a furnace oven at $800^{\circ} \mathrm{C}$ for $2 \mathrm{~h}$ with the resulting products of weight $202 \mathrm{~g}$ were separated from the sand, placed in a crucible and further heated in a steam sterilizer at $120^{\circ} \mathrm{C}$ for $2 \mathrm{~h}$. The resulting product was then crushed and sieved in mesh size No $40(425 \mu \mathrm{m})$ and mesh size $8(2.36 \mathrm{~mm})$.

\section{Chemical activation of the activated carbons}

The procedure for the chemical activation of the produced activated carbon was according to the procedure outlined by Ademiluyi et al. [16]. The produced activated carbon was carefully weighed and put in beaker containing $120 \mathrm{~cm}^{3}$ of $0.1 \mathrm{M} \mathrm{HCI}$. The content of the beaker was thoroughly mixed until it forms a paste. The paste was then transferred to a crucible and placed in a Muffle furnace heated to $800^{\circ} \mathrm{C}$ for $2 \mathrm{~h}$. The sample was then cooled at room temperature, washed with distilled water until the $\mathrm{pH}$ of the draining water is in the range of 6-7. The sample was then dried in an oven at $105^{\circ} \mathrm{C}$ for $3 \mathrm{~h}$. The final product was kept in an air tight glass container until ready for use.

\section{Procurement of discharged petroleum product contaminated industrial water}

Industrial waste water used for the adsorption studies were collected thrice (coded A, $\mathrm{B}$ and $\mathrm{C}$ ) at different times (7 days intervals) from a petroleum refining industry in Port Harcourt, Rivers State in Nigeria. The sample was collected after mechanical and biological treatment has been carried out on sample in a pre-rinsed 10 litre plastic containers, sealed and transported to the laboratory for analysis.

\section{Adsorption of organic contaminants using the produced activated carbon (PAC)}

$100 \mathrm{ml}$ of the waste water samples in batches were mixed with 1.00, 2.00, 3.00, 4.00 and $5.00 \mathrm{~g}$ respectively of the produced activated carbon in $250 \mathrm{ml}$ Erlenmeyer flasks. The mixtures were shaken thoroughly and intermittently for $2 \mathrm{~h}$ before being filtered using a Whatman filter paper No 1 size to remove the carbon. The characteristics of the industrial waste water was analysed before (negative control) and after treatment with the produced activated carbon (PAC). Physicochemical parameters of the representative samples such as temperature, odour, appearance, density, $\mathrm{pH}$, chemical oxygen demand (COD), dissolved oxygen (DO), biological oxygen demand (BOD), conductivity, turbidity, total dissolved solids (TDS), chloride, sulphate, total hardness, calcium and magnesium concentrations at the varying dosages of the activated carbon used were performed within a period of 7 and 10 days using methods described by the American 
Public Health Association (APHA) [17, 18]. The same procedure was performed for sample A, B and C and the procured commercial activated carbon (CAC) (positive control) with the mean result taken to serve as the representative result.

\section{Results and Discussion}

The physicochemical characteristics of the discharged industrial water treated with different dose of the adsorbent with reference to the commercial sample is presented in Table 1.

Table 1. Physicochemical characteristics of the discharged industrial water

\begin{tabular}{|c|c|c|c|c|}
\hline Parameters & $\begin{array}{c}\text { PAC Mean Value } \\
\text { (Before Analysis) }\end{array}$ & $\begin{array}{c}\text { PAC Mean Value } \\
\text { (After Analysis) }\end{array}$ & $\begin{array}{c}\text { 5.00 g of } \\
\text { CAC } \\
\text { Value }\end{array}$ & Standard \\
\hline Temperature $\left({ }^{\circ} \mathrm{C}\right)$ & 34 & 28 & 28 & $38^{\mathrm{RS}}$ \\
\hline Odour & Offensive & Totally removed & $\begin{array}{c}\text { Totally } \\
\text { removed }\end{array}$ & NS \\
\hline Appearance & Not clear & Clear & Clear & NS \\
\hline Density (kg/m $\left.\mathrm{m}^{3}\right)$ & 843 & $\begin{array}{c}(800),(800),(820), \\
(820),(840)\end{array}$ & $\mathrm{NS}$ & $\mathrm{NS}$ \\
\hline $\mathrm{pH}$ & 5.2 & $\begin{array}{c}(5.4),(5.8),(6.5), \\
(6.9),(7.3)\end{array}$ & 7.7 & $6.5-8.5^{\mathrm{WHO}}$ \\
\hline COD (mg/l) & 373 & $\begin{array}{c}(371),(343),(311), \\
(287),(261)\end{array}$ & 148 & $130^{\mathrm{RS}}$ \\
\hline DO (mg/l) & 4.1 & $\begin{array}{c}(6.1),(6.9),(7.4), \\
(8.3),(8.8)\end{array}$ & 9.1 & $14^{\mathrm{RS}}$ \\
\hline BOD (mg/l) & 52.6 & $\begin{array}{c}(45.6),(41.8),(37.4), \\
(33.3),(28.8)\end{array}$ & 15.5 & $10-20^{\mathrm{RS}}$ \\
\hline Conductivity \\
$(\mu \mathrm{S} / \mathrm{cm})$
\end{tabular}




\begin{tabular}{|c|c|c|c|c|}
\hline TDS (mg/l) & 878 & $\begin{array}{c}(857),(821),(798), \\
(746),(664)\end{array}$ & 354 & $0-500^{\mathrm{WHO}}$ \\
\hline Chloride (mg/l) & 765.1 & $\begin{array}{c}(672.8),(522.5), \\
(482.5),(442.5), \\
(346.9)\end{array}$ & 248 & $250^{\mathrm{WHO}}$ \\
\hline Sulphate (mg/l) & 235.2 & $\begin{array}{c}(222.8),(197.6), \\
(187.3),(172.4), \\
(165.7)\end{array}$ & 153.6 & $150^{\mathrm{WHO}}$ \\
\hline $\begin{array}{c}\text { Total hardness } \\
\text { (mg of CaCO } \\
\text { per litre) }\end{array}$ & 17.56 & $\begin{array}{c}(24.4),(39.6),(41.6), \\
(47.9),(57.7)\end{array}$ & 195.2 & $200-250^{\mathrm{WHO}}$ \\
\hline Calcium (mg/l) & 397.60 & $\begin{array}{c}(391.1),(387.6), \\
(381.3),(379.7), \\
(377.7)\end{array}$ & 197,5 & $75-200^{\mathrm{WHO}}$ \\
\hline \begin{tabular}{c} 
Magnesium (mg/l) \\
\hline
\end{tabular} & 12.80 & $\begin{array}{c}(19.4),(21,7),(23.8), \\
(25.7),(28.9)\end{array}$ & 31.3 & $30-150^{\mathrm{WHO}}$ \\
\hline
\end{tabular}

Key: PAC $=$ Produced activated charcoal, $\mathrm{CAC}=$ Commercial activated carbon, WHO $=$ World Health Organization [19], RS = Refinery specification. NS = No specification. The first, second, third, fourth and fifth brackets represent the mean results for 1.00, 200, 3.00, 4.00 and $5.00 \mathrm{~g}$ of the produced adsorbent respectively.

All the examined parameters except $\mathrm{pH}$ were found to be outside the prescribed ranges set by the World Health Organization (WHO) [19]. This is line with similar observations made by Horsfall and Spiff [20] and Odu et al. [21]. The results however are evidence of the ability of the adsorbent to remove the contaminant from the industrial waste samples by attaching to the contaminant molecules at an available adsorption site when higher concentrations of PAC were employed. The result showed that there was a decrease in the concentration of organic pollutants with increasing concentration of the activated carbon dose used. The adsorptive property of the PAC may have been influenced by factors such as particle-size distribution, concentration of the adsorbent, surface area and contact time. The CAC showed a better adsorbing potential at the highest concentration of PAC employed for the study since it possess a better surface area to volume ratio and adsorbing potentials similar to the report of Olafadehan and Aribike [1] and Snoeyink and Summers [22] who treated industrial waste water with commercial activated carbon.

The temperature of the wastewater after adsorption process was constant due to the 
fact that, the analysis was carried out at room temperature. The result showed that the PAC corrected the $\mathrm{pH}$ to specification as against the effluents before analysis. There was a remarkable decrease in the amount of total dissolved solid after treatment. It was reduced from 878 before treatment with the PAC to 857 and 664 when $1.00 \mathrm{~g}$ (the lowest) and $5.00 \mathrm{~g}$ (the highest) concentration of the produced adsorbent was used. With respect to $\mathrm{COD}$ in the discharged waste water before and after treatment, it can be observed that the COD was reduced from $373 \mathrm{mg} / \mathrm{l}$ to $371 \mathrm{mg} / \mathrm{l}$ and $261 \mathrm{mg} / \mathrm{l}$ when 1.00 $\mathrm{g}$ and $5.00 \mathrm{~g}$ of the PAC was used respectively. The result obtained shows that the dissolved oxygen was increased from $6.1 \mathrm{mg} / \mathrm{l}$ before treatment to $8.8 \mathrm{mg} / \mathrm{l}$ when the highest concentration of the adsorbent was used for $2 \mathrm{~h}$ contact duration. The BOD was reduced from $52.6 \mathrm{mg} / \mathrm{l}$ before treatment to $28.8 \mathrm{mg} / \mathrm{l}$ when the highest concentration of the adsorbent was used for $2 \mathrm{~h}$ contact duration. This thou higher compares favorably with the standard adsorbent used. The result presented in Table 1 showed that the turbidity was relatively removed. As regards other parameters like conductivity, chloride, sulphate among others, the results from this show showed the potential of the PAC to correct their concentration to specifications. The activated carbon produced from $H$. crepitans seeds completely removed the offensive odour in the industrial waste water, with clear appearance.

\section{Conclusions}

H. crepitans seeds used as precursor successfully produced activated carbon locally. The adsorption tests clearly revealed that the locally prepared activated carbon can be used as effective and low cost adsorbent. Though the contaminants removal efficiency increases with a corresponding increase in the concentration of the locally prepared activated carbon, its potentials were less but comparable to that of the commercial procured activated carbon used as standard. Therefore, the effectiveness of the activated carbon produced from $H$. crepitans seeds in the removal of organic contaminants has further been validated.

\section{Conflict of Interest Statement}

The authors declare that there is no conflict of interest that could be perceived as prejudicating the impartiality of research reported. 


\section{References}

[1] O. A. Olafadehan and D. S. Aribike, Treatment of industrial wastewater effluent, Journal of Nigerian Society of Chemical Engineers 19 (2000), 50-53.

[2] A. Fakhru'l-Razi, P. Alireza, C. H. Luqman, R. A. B. Dayang, S. M. Sayed and Z. A. Zurina, Review of technologies for oil and gas produced water, Journal of Hazardous Materials 170 (2009), 530-551. https://doi.org/10.1016/j.jhazmat.2009.05.044

[3] Muhammed H. Al-Malack, Treatment of petroleum refinery wastewater using crossflow and immersed membrane processes, Desalination and Water Treatment 51 (2013), 69856993. https://doi.org/10.1080/19443994.2013.778798

[4] C. O. Igwe, A. A. L. Saadi and S. E. Ngene, Optimal options for treatment of produced water in offshore platforms, Journal of Pollution Effect and Control 1(1) (2013), 1-5.

[5] J. P. Ray and F. Rainer Engelhardt, Produced Water: Technological/Environmental Issues and Solutions, Vol. 46, Environmental Science Research, New York, NY, USA: Springer, 1992. https://doi.org/10.1007/978-1-4615-2902-6

[6] T. Sirivedhin, J. McCue and. L. Dallbauman, Reclaiming produced water for beneficial use: salt removal by electrodialysis, Journal of Membrane Science 243(1-2) (2004), 335343. https://doi.org/10.1016/j.memsci.2004.06.038

[7] J. C. Perez-Casanova, D. Hamoutene, S. Samuelson, K. Burt, T. L. King and K. Lee, The immune response of juvenile Atlantic cod (Gadus morhua L.) to chronic exposure to produced water, Mar. Environ. Res. 70 (2010), 26-34.

https://doi.org/10.1016/j.marenvres.2010.02.005

[8] M. Nasiri and I. Jafari, Produced water from oil-gas plants: a short review on challenges and opportunities, Periodica Polytechnica Chemical Engineering 61(2) (2017), 73-81. https://doi.org/10.3311/PPch.8786

[9] T. A. Saleh and V. K. Gupta, Processing methods, characteristics and adsorption behaviour of tire derived carbons: A review, Advance in Colloid and Interface Science 211 (2014), 93-101. https://doi.org/10.1016/j.cis.2014.06.006

[10] J. D. Arthur, B. G. Langhus and C. Patel, Technical summary of oil and gas produced water treatment technologies, All Consulting, LLC, Tulsa, 2005.

[11] Hear Organization: http://www.hear.org/pier/species/hura-crepitans.html (accessed 2019).

[12] Tropilab Inc.: http://www.trobilab/hura-cre.html (accessed 2019).

[13] M. T. Ravanchi, T. Kaghazchi and A. Kargari, Application of membrane separation 
processes in petrochemical industry, a review, Desalination 235(1-3) (2009), 199-244. https://doi.org/10.1016/j.desal.2007.10.042

[14] I. A. W. Tan, A. L. Ahmad and B. H. Hameed, Preparation of activated carbon from coconut husk: Optimization study on removal of 2, 4, 6-trichlorophenol using response surface methodology, Journal of Hazardous Materials 153 (2008), 709-717. https://doi.org/10.1016/j.jhazmat.2007.09.014

[15] M. Y. R. Ali, F. M. Saleh and A. Zubair, Adsorption of acenaphthene using date seed activated carbon, Journal of Environmental Science and Technology 11(1) (2018), 10-15. https://doi.org/10.3923/jest.2018.10.15

[16] F. T. Ademiluyi, S. A. Amadi and N. J. Amakama, Adsorption and treatment of organic contaminants using activated carbon from waste Nigerian bamboo, J. Appl. Sci. Environ. Manag. 13(3) (2009), 39-47. https://doi.org/10.4314/jasem.v13i3.55351

[17] APHA, Standard Methods for the Examination of Wastewater, America Public Health Association, 1989.

[18] L. S. Clesceri, A. E. Greenberg and T. Rhodes, eds., Standard Methods for the Examination of Water and Wastewater, 17th ed., American Public Health, 1989.

[19] World Health Organsiation (WHO), International Standards for Drinking-water Quality, Geneva: WHO, 1985.

[20] M. Horsfall and A. I. Spiff, Principles of Environmental Pollution (with Physical, Chemical and Biological Emphasis), 1st revised ed., Port Harcourt, Nigeria: Metroprints Ltd., 2001, pp. 206-217.

[21] C. T. Odu, O. F. Esuruoso, L. C. Nwoboshi and J. A. Ogunwale, Environmental Study of the Nigerian AGIP Oil Company Operational Areas: Soils and Fresh-water vegetation, Milan, Italy, 1985.

[22] V. L. Snoeyink and R. S. Summers, Adsorption of organic compounds, in: R. D. Letterman, ed., Water Quality and Treatment: A Hand Book of Community Watersupplies, New York, USA: Mc-Graw Hill, 1999. 